\title{
Size Does Matter: The Role of Patient's Body Surface Predicting Surgical Difficulty in Total Knee Replacement
}

\author{
Ignacio Moya*1,3, Eduardo Tornero ${ }^{2,3,4}$, Montserrat Tió ${ }^{2,3,4}$, Andrés Combalia ${ }^{2,3,4}$, Sergi Sastre ${ }^{2,3,4}$ and Luís \\ Lozano $^{2,3,4}$
}

${ }^{1}$ Hospital de Sant Joan Despí Moisés Broggi - Consorci Sanitat Integral. Carrer de Jacint Verdaguer, Spain

${ }^{2}$ Hospital Clinic de Barcelona. Carrer de Villarroel 170, 08036, Barcelona, Spain

${ }^{3}$ Universitat de Barcelona, Spain

IInstitut d' Investigacions Biomèdiques August Pi I Sunyer (IDIBAPS), Spain

Submission: July 04, 2019; Published: July 17, 2019

*Corresponding author: : Ignacio Moya, Hospital de Sant Joan Despí Moisés Broggi - Consorci Sanitat Integral, Carrer de Jacint Verdaguer, 90 , 08970. Sant Joan Despí, Barcelona, Spain

\section{Abstract}

Introduction: Total knee replacement (TKR) is a frequently performed surgery with reported very positive outcomes. However, the difficulty of TKR surgery can vary greatly between patients. Many factors have been related to higher surgical difficulty in TKR, but the role of patient anthropometry is still unclear. Although patient Body Mass Index (BMI) is known to affect the postoperative outcome after TKR, it has not proved to be a reliable predictor of surgical difficulty. The aim of this work was to state whether if the patient's overall size, measured with the patient's body surface, had a direct impact on surgical difficulty.

Material and methods: We retrospectively reviewed 250 patients who underwent TKR surgery in our center from January 2014 to October 2014. The following data were collected from the pre-anesthesia evaluation sheet: age (in years), weight (in kilograms), height (in centimeters), BMI (using the formula weight/height2), body surface (using Dubois' formula [20], $\mathrm{x}=0.007184 \mathrm{x}$ weight $(\mathrm{kg}) 0.425 \mathrm{x}$ height $(\mathrm{cm}) 0.725)$ expressed in $\mathrm{m}^{2}$, and surgical times. Statistical analyses were performed.

Results: After the analyses we found there wasn't association between high BMI and higher surgical times. However, there was a direct relation between surgical times and patient body surface values. These findings were statistically significant.

Conclusion: In our experience, the patient's body surface is a reliable predictor of surgical difficulty.

Keywords: Surgical; Difficulty; Knee; Obesity; Anthropometry; Body; Surface

\section{Introduction}

Total knee replacement (TKR) surgery is one of the most frequently performed surgeries in orthopaedic operating rooms [1]. Many aspects related to the patients who have undergone surgery have been studied in order to determine the factors that affect surgical difficulty [2-9], complications [10-14] and functional outcome $[15,16]$. Metabolic syndrome is known to increase postoperative complications $[10,11,17]$ and the body mass index (BMI) affects both postoperative complications and the functional results $[5,10,11,15,16]$ to the extent that some authors consider that patients would have to be treated using specialized equipment depending on their degree of obesity [18].

Anthropometry is a science that uses various morphological measurements of the human body in an attempt to find practical applications for them in the diagnosis and treatment of patients. One of the most common anthropometric measures used in order to classify the degree of obesity is the body mass index (BMI) [19], since the WHO recommends its use to measure the risk factor for cardiovascular diseases. The body mass index gives an idea of the patient's fat mass and is calculated by dividing the patient's weight by the square of their height. However, several publications state that the patient's BMI is not a measurement that has succeeded in finding a relationship between the patient's morphology and the duration of a TKR operation [5,7]. The interest in determining preoperatively which patients carry a greater surgical difficulty has, as its purpose, the possibility of foreseeing the need for greater resources in the operating room. Our hypothesis is that the patient' overall size, measured with the patient's body surface, is a directly associated to the degree 
of surgical difficulty, and the main purpose of this work is to determine whether if it is so.

\section{Material and Methods}

With the idea of determining which anthropometric parameters affected the surgical time of the TKR operation, data from patients who underwent TKR surgery between January 2014 and October 2014 in the knee unit of the Hospital Clinic of Barcelona were collected. All surgeries were performed by the same surgeon with a wide experience in TKR surgery in obese patients, and on all of them the same surgical technique in terms of ligament release and balancing was performed. In all cases, cemented components were implanted. The surgical approach was a direct anterior transvastus approach in all cases. The resurfacing of the patella was performed according to the severity of the osteoarthritis of the femoro-patellar joint assessed both radiologically in preoperative X-Rays and intraoperatively. Bone grafting was not performed in any case.

The data collection was prospective. The inclusion criteria were patients who were operated on for total arthroplasty of the knee and signed an informed consent for the use of the data obtained from their clinical history and for the performance of the necessary anthropometric measurements. The exclusion criteria were patients operated on for unicompartmental knee arthroplasty or revision prosthetic surgery, patients on whom the ischemia cuff could not be used during the operation or patients who did not consent to the use of their data.

The surgical difficulty is determined by surgical time, which was determined by the minutes that the tourniquet cuff remained inflated during the operation. The cuff is placed at the root of the thigh that is being operated on and is inflated to a pressure of $250 \mathrm{mmHg}$ moments before the beginning of the cutaneous incision and is deflated once the prosthetic components have been cemented. The following data were collected from the pre-anesthesia evaluation sheet: age (in years), weight (in kilograms), height (in centimeters), BMI (using the formula weight/height2), body surface (using Dubois' formula [20], $\mathrm{x}$ $=0.007184 \mathrm{x}$ weight $(\mathrm{kg}) 0.425 \mathrm{x}$ height $(\mathrm{cm}) 0.725)$ expressed in $\mathrm{m} 2$. In the operating room, before spinal anesthesia was performed, the anthropometric indexes of the knee were determined [6]. These are calculated by measuring the length radius of the limb (measured from the anterosuperior iliac crest to the center of the ankle, expressed in centimetres) and the suprapatellar perimeter (measured at a point located $4 \mathrm{~cm}$ proximal to the upper edge of the patella) and the infrapatellar perimeter (measured at the level of the anterior tibial tuberosity), both expressed in centimeters. The length radius of the leg and the suprapatellar perimeter give us the suprapatellar index and the length radius and the infrapatellar perimeter give us the infrapatellar index. All measurements were made with an elastic measuring tape and a consistency test among the people carrying out the measurements was performed.
Expert surgeons of the knee unit following the same surgical protocol performed all surgeries. The prosthesis models used cemented femoral components, while the tibial component was or was not cemented based on the patient's characteristics and the patella was prosthetisised based on the degree of arthritis that it presented. The BMI values were separated into three different groups according to the World Health Organization (WHO) classification [19]: non-obese $\left(<30 \mathrm{~kg} / \mathrm{m}^{2}\right)$, obese (between 30 and $34,9 \mathrm{~kg} / \mathrm{m}^{2}$ ) and seriously and morbidly obese (35 $\mathrm{kg} / \mathrm{m}^{2}$ or more). The normal values of body surface [20] were $1.9 \mathrm{~m}^{2}$ for men and $1.6 \mathrm{~m} 2$ for women.

\section{Statistical Analysis}

According to the Kolmogorov-Smirnov test of normality, continuous variables with normal distribution (weight, height, body surface, BMI, limb length) were expressed as mean and standard deviation (SD) and were compared by the Student's T-test, whereas continuous variables with non-normal (age, surgical time, suprapatellar perimeter, ATT perimeter and) distribution were expressed as median and interquartile range (IQR) and were compared by the Mann-Whitney U test. Surgical time was classified according to the 75 th percentile as long surgery (surgical time $\geq 60$ minutes) and normal surgery (surgical time $<60$ minutes). Qualitative variables (gender and ASA classification classified as ASA I-II and ASA III-IV) were described by absolute frequencies and percentages and were compared by the Chi-square test or Fisher's exact test when necessary. Correlation curves between continuous variables were estimated by testing linear, logarithmic, exponential and quadratic equation models. A forward stepwise logistic regression model was performed to identify independent predictors of failure. Interactions between terms within the logistic model were tested and goodness of fit was explored based on the Hosmer-Lemeshow test. Statistical significance was defined as a two-tailed $<0.05$. The analysis was performed using SPSS, version 20.0 (SPSS, Inc., Chicago, IL, USA). Multivariate analysis was performed to assess the direct impact of the body surface variable on surgical difficulty.

\section{Results}

A total of 250 patients met the inclusion criteria of the study. The median (IQR) age of the cohort was 72 (67-77) years and $172(68.9 \%)$ were female. The mean (SD) weight and height were 78.1 (13.4) kg and 159.8 (9.2) cm, respectively. One hundred and nineteen $(47.5 \%)$ patients presented a BMI $<30 \mathrm{~kg} / \mathrm{m}^{2}$ and $41(16.7 \%)$ patients presented a BMI $\geq 35 \mathrm{Kg} / \mathrm{m}^{2}$. The median (IQR) surgical time was 52 (47-60) and 73 (29.2\%) cases were categorized as long surgery.

Table 1 shows the main characteristics of patients according to outcome. Median age was younger in the long surgery group ( 71 vs. 73 years, $p=0.022$ ) and male gender showed a significant association with long surgery in comparison to female gender ( 32 vs. $41, \mathrm{p}=0.006$ ). Patients in the long surgery group had higher mean weight (82.1 kg vs. $76.6 \mathrm{~kg}, \mathrm{p}=0.003$ ), 


\section{Orthopedics and Rheumatology Open Access Journal (OROAJ)}

higher mean height (163 cm vs. $159 \mathrm{~cm}, \mathrm{p}<0.001)$ and higher mean body surface ( $1.875 \mathrm{~m} 2$ vs. $\left.1.783 \mathrm{~m}^{2}, \mathrm{p}<0.001\right)$, whereas no differences were found with regard to BMI value (30.5 vs. $\left.30.8 \mathrm{Kg} / \mathrm{m}^{2}, \mathrm{p}=0.608\right)$. No significant differences were found regarding other anthropomorphic measurements of the limb. Figure 1 shows the relationship between body surface and time of surgical time (linear equation, $\mathrm{R} 2=0.060$, p<0.001). Finally, all variables studied in the univariate analysis were included in a multivariate analysis. A step-wise forward logistic regression model identified body surface (OR: 16.265, 95\%CI: 3.23781.719 ) as the only variable independently associated with long surgery (Hosmer-Lemeshow test, $\mathrm{p}=0.880$ ).

Table 1: Characteristics of patients according to outcome ( ${ }^{*}$ surgical time was classified according to the $75^{\text {th }}$ percentile as Long Surgery when surgical time $\geq 60$ minutes and Normal Surgery when surgical time $<60$ minutes).

\begin{tabular}{|c|c|c|c|}
\hline & Normal Surgery* $(\mathrm{N}=177)$ & Long Surgery* $(\mathrm{N}=73)$ & p-value \\
\hline Median (IQR) age (years) & $73(67-77.75)$ & $71(64-75)$ & 0.022 \\
\hline \multicolumn{4}{|l|}{ Gender } \\
\hline Male & $46(26.0)$ & $32(43.8)$ & \multirow{2}{*}{0.006} \\
\hline Female & $131(74.0)$ & $41(56.2)$ & \\
\hline ASA classification $=$ III or IV & $33(19.1)$ & $14(19.2)$ & 1.000 \\
\hline Mean (SD) weight (Kg) & $76.6(12.8)$ & $82.1(14.3)$ & 0.003 \\
\hline Mean (SD) height $(\mathrm{cm})$ & $158.6(8.8)$ & $163.1(9.5)$ & $<0.001$ \\
\hline Mean (SD) body surface $\left(\mathrm{m}^{2}\right)$ & $1.783(0.169)$ & $1.875(0.193)$ & $<0.001$ \\
\hline Mean (SD) BMI $\left(\mathrm{Kg} / \mathrm{m}^{2}\right)$ & $30.5(5.0)$ & $30.8(4.7)$ & 0.608 \\
\hline $\mathrm{BMI}<30$ & $90(50.8)$ & 29 (39.7) & 0.109 \\
\hline $\mathrm{BMI} \geq 30$ and $<35$ & $58(32.8)$ & $32(43.8)$ & 0.112 \\
\hline $\mathrm{BMI} \geq 35$ & $29(16.4)$ & $12(16.4)$ & 0.992 \\
\hline Mean (SD) limb length (cm) & $83.8(7.2)$ & $84.7(5.2)$ & 0.372 \\
\hline Mean (SD) suprapatellar index & $1.81(0.28)$ & $1.80(0.30)$ & 0.835 \\
\hline Mean (SD) infrapatellar index & $2.30(0.29)$ & $2.33(0.27)$ & 0.568 \\
\hline
\end{tabular}

\section{Discussion}

The most relevant result of this study is that the duration of the TKR operation is related independently to the patient's body surface. Up until now, studies have been directed to determine whether if the patient's BMI (weight/height2 ratio) affected the length of the operation [2-8,12,21,22]. While the relationship between the $\mathrm{BMI}$ and postoperative complications is unquestionable $[5,10,11,15,16]$, the relationship between the BMI and the length of the surgery has been questioned in various articles [5,7]. The present study shows that, if the BMI is used, we penalize the shorter patients in comparison to the patients weighing the same who are taller. Both patient weight and height affect the surgical difficulty, as we have seen in the univariate analysis. Thus, the value that relates them directly (body surface) is the one that suggests whether if a patient is "bigger" and will be harder to operate on. For instance, our results show that the surgical difficulty (and surgical time, consequently) would be lower in a shorter patient, even though if his/her BMI is high, than in a tall, heavy ("big") patient who has a lower BMI than the first one. In cardiology one speaks of the "obesity paradox" [23$25]$, even though in recent studies obese patients have a lower mortality after myocardial infarct. Some of the explanations that are given in the studies that analyse this paradox note that one must not consider only the patient's BMI in order to find out what his or her nutritional state is. Something similar happens regarding the surgical time and the patient's BMI. Determination of the body surface will be helpful in identifying the type of patient who will require more resources and surgical time.

The BMI, which reflects the patient's adiposity and the existence of an associated metabolic syndrome, will determine a patient who may present with postoperative complications and worse functional results, and for this reason its determination is paramount $[5,9-11,15,16]$. Determination of the anthropometry of the knee that is to be operated on by calculating the anthropometric indices described in the literature [6,7] has not proven helpful when it comes to identifying patients in which the surgery is going to last longer. It is not only the size and morphology of the knee that is going to make exposure of the operating field more difficult, but also the patient's overall size that is going to make management in the operating room difficult during surgery. That overall size, in other words, how "big" the patient is, is not necessarily linked to a high BMI, since taller patients might have normal BMI scores despite having high weights. However, these patients, who are going to pose a greater difficulty in terms of surgical management, are also the ones with higher body surface scores. In that sense, we believe that body surface is more reliable than BMI when it comes to predicting surgical difficulty.

Gender is also a factor that affects surgical difficulty. Male sex has been related to a worse prognosis as well as to a higher possibility of postoperative complications $[13,14]$, and in our study we found that it was also associated to longer surgical times. Since male patients tend to be higher and heavier, their 


\section{Orthopedics and Rheumatology Open Access Journal (OROAJ)}

body surface is also usually higher than in females. For this reason, it is a subgroup of patients that must be taken especially into account in terms of surgical difficulty. Knee arthritis and consequently replacement surgery is more frequent in females. The reason for this is that several hormonal factors make arthritis more likely to appear than in males [26]. Likewise, obesity is also more frequent in women.

In our experience, younger age was also found to have a direct impact in surgical difficulty, leading to longer surgical times. As stated, before about gender, young patients also tend to be higher and heavier than old patients, thus leading to higher body surface scores. It is for that reason that we believe that younger patients had longer surgical times than older ones.

\section{Conclusion}

The patient's overall size, which is measured with patient body surface, is a reliable surgical difficulty predictor that must be taken into consideration prior to the surgery in order to assess the resources that the surgeon might need. There is a cohort, which consists of male patients with high body surface that represents an especially high risk of longer, more difficult TKR surgeries.

\section{Author Contributions}

Luis Lozano conceived of the presented idea and developed the theory. All authors contributed to the analytical methods, encouraged and supervised the findings of this work. Also, all authors discussed the results and contributed to the final manuscript.

\section{Acknowledgement}

The authors would like to express their gratitude to the university of Barcelona (UB) and Hospital Clinic de Barcelona for their support during this work. No funding sources were linked to this work.

\section{Conflicts of Interest}

Ignacio Moya, Eduardo Tornero, Montserrat Tio, Andrés Combalia, Sergi Sastre and Luis Lozano declare that they hold no conflicts of interest regarding the present work.

\section{References}

1. Culliford D, Maskell J, Judge A, Cooper C, Prieto-Alhambra D, et al. (2015) Future projections of total hip and knee arthroplasty in the UK: results from the UK Clinical Practice Research Datalink. Osteoarthritis Cartilage Osteoarthritis Cartilage 23(4): 594-600.

2. Batsis JA, Naessens JM, Keegan MT, Huddleston PM, Wagie AE, et al. (2010) Body mass index and the impact on hospital resource use in patients undergoing total knee arthroplasty. J Arthroplasty 25(8): $1250-1255$

3. Gadinsky NE, Manuel JB, Lyman S, Westrich GH (2012) Increased operating room time in patients with obesity during primary total knee arthroplasty: conflicts for scheduling. J Arthroplasty 27(6): $1171-1176$

4. Liabaud B, Patrick DA Jr, Geller JA (2013) Higher body mass index leads to longer operative time in total knee arthroplasty. J Arthroplasty 28(4): 563-565.
5. Ledford CK, Ruberte Thiele RA, Appleton JS Jr, Butler RJ, Wellman SS, et al. (2014) Percent body fat more associated with perioperative risks after total joint arthroplasty than body mass index. J Arthroplasty $29(9$ Suppl): $150-154$.

6. Lozano LM, Núñez M, Segur JM, Maculé F, Sastre S, et al. (2008) Relationship between knee anthropometry and surgical time in total knee arthroplasty in severely and morbidly obese patients: a new prognostic index of surgical difficulty. Obes Surg 18(9): 1149-1153.

7. Lozano LM, Tió M, Rios J, Sanchez-Etayo G, Popescu D, et al. (2014) Severe and morbid obesity (BMI $\geq 35 \mathrm{~kg} / \mathrm{m}(2)$ ) does not increase surgical time and length of hospital stay in total knee arthroplasty surgery. Knee Surg Sports Traumatol Arthrosc 23(6): 1713-1719.

8. Raphael IJ, Parmar M, Mehrganpour N, Sharkey PF, Parvizi J (2013) Obesity and operative time in primary total joint arthroplasty. J Knee Surg 26(2): 95-100.

9. Winiarsky R, Barth P, Lotke P (1998) Total knee arthroplasty in morbidly obese patients. J Bone Joint Surg Am 80(12): 1770-1774.

10. Dowsey MM, Choong PF (2009) Obese diabetic patients are at substantial risk for deep infection after primary TKA. Clin Orthop Relat Res 467(6): 1577-1581.

11. Malinzak RA, Ritter MA, Berend ME, Meding JB, Olberding EM, et al. (2009) Morbidly obese, diabetic, younger, and unilateral joint arthroplasty patients have elevated total joint arthroplasty infection rates. J Arthroplasty 24: 84-88.

12. Peersman G, Laskin R, Davis J, Peterson MG, Richart T (2006) Prolonged operative time correlates with increased infection rate after total knee arthroplasty. HSS J 2(1): 70-72.

13. Rasouli MR, Restrepo C, Maltenfort MG, Purtill JJ, Parvizi J (2014) Risk factors for surgical site infection following total joint arthroplasty.J Bone Joint Surg Am 96(18): e158.

14. Tornero E, García-Ramiro S, Martínez-Pastor JC, Bori G, Bosch J, et al (2015) Prophylaxis with teicoplanin and cefuroxime reduces the rate of prosthetic joint infection after primary arthroplasty. Antimicrob Agents Chemother 59(2): 831-837.

15. Nuñez M, Lozano L, Nunez E, Segur JM, Sastre S (2011) Factors influencing health-related quality of life after TKA in patients who are obese. Clin Orthop Relat Res 469(4): 1148-1153.

16. Núñez M, Lozano L, Núñez E, Sastre S, Luis Del Val J, et al. (2011) Good quality of life in severely obese total knee replacement patients: a casecontrol study. Obes Surg 21(8): 1203-1238.

17. Reátegui D, Sanchez-Etayo G, Núñez E, Tió M, Popescu D, et al. (2015) Perioperative hyperglycaemia and incidence of post-operative complications in patients undergoing total knee arthroplasty. Knee Surg Sports Traumatol Arthrosc 23(7): 2026-2031.

18. Schwartz AJ (2013) CORR Insights (B): Bariatric orthopaedics: total knee arthroplasty in super-obese patients (BMI $>50 \mathrm{~kg} / \mathrm{m} 2$ ). Survivorship and complications.Clin Orthop Relat Res 471(11): 3531-3532.

19. World Health Organisation (2006) Obesity and overweight.

20. Mosteller RD (1987) Simplified calculation of body-surface area. N Engl J Med 317: 1098.

21. Epstein AM, Read JL, Hoefer M (1987) The relation of body weight to length of stay and charges for hospital services for patients undergoing elective surgery: a study of two procedures. Am J Public Health 77(8): 993-997.

22. Jonas SC, Smith HK, Blair PS, Dacombe P, Weale AE (2013) Factors influencing length of stay following primary total knee replacement in a UK specialist orthopaedic centre. Knee 20(5): 310-315.

23. Gastelurrutia P, Lupón J, de Antonio M, Zamora E, Domingo M, et al (2014) Body mass index, body fat, and nutritional status of patients with heart failure: The PLICA study. Clin Nutr 34(6): 1233-1238. 
24. Khalid U, Ather S, Bavishi C, Chan W, Loehr LR, et al. (2014) Pre-Morbid Body Mass Index and Mortality After Incident Heart Failure: The ARIC Study. J Am Coll Cardiol 64(25): 2743-2749.

25. Zafrir B, Goren Y, Salman N, Amir O (2015) Comparison of body mass index and body surface area as outcome predictors in patients with systolic heart failure. Cardiol J 22(4): 375-381.

This work is licensed under Creative Commons Attribution 4.0 License

DOI: 10.19080/OROAJ.2019.14.555890
26. Felson DT, Lawrence RC, Dieppe PA, Hirsch R, Helmick CG, et al. (2000) Osteoarthritis: new insights. Part 1: the disease and its risk factors. Ann Intern Med 133(8): 635-646.

\section{Your next submission with Juniper Publishers will reach you the below assets}

- Quality Editorial service

- Swift Peer Review

- Reprints availability

- E-prints Service

- Manuscript Podcast for convenient understanding

- Global attainment for your research

- Manuscript accessibility in different formats

( Pdf, E-pub, Full Text, Audio)

- Unceasing customer service

Track the below URL for one-step submission https://juniperpublishers.com/online-submission.php 